\title{
Bir üniversite hastanesi noroloji yoğun bakım ünitesinde gelişen enfeksiyonların değerlendirilmesi
}

\section{Evaluation of nosocomial infections in a neurological intensive care unit of a university hospital}

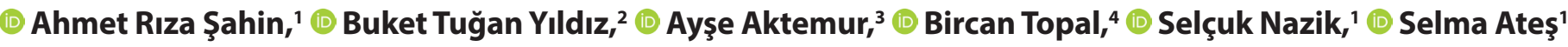 \\ 'Kahramanmaraş Sütçü İmam Üniversitesi Tıp Fakültesi, Enfeksiyon Hastalıkları ve Klinik Mikrobiyoloji Anabilim Dalı, Kahramanmaraş, Türkiye \\ ${ }^{2}$ Kahramanmaraş Sütçü İmam Üniversitesi Tıp Fakültesi, Nöroloji Anabilim Dalı, Kahramanmaraş, Türkiye \\ ${ }^{3}$ Kahramanmaraş Necip Fazıl Hastanesi, Enfeksiyon Hastalıkları Kliniği, Kahramanmaraş, Türkiye \\ ${ }^{4}$ Kahramanmaraş Sütçü İmam Üniversitesi Tıp Fakültesi, Enfeksiyon Kontrol Komitesi Hemşireliği, Kahramanmaraş, Türkiye
}

\section{Özet}

Amaç: Hastane enfeksiyonları (HE) sıklığı, uzamış yaşam, gelişen teknoloji, artmış invaziv girişimler ve uzamış yatış nedeniyle giderek artmaktadır. Yoğun bakım üniteleri (YBÜ) HE'nin en sık görüldüğü hastane birimleridir. Nöroloji YBÜ (NYBÜ)'de gelişen HE'ler altta yatan primer hastalıklar, genel durum bozukluğu, artmış invaziv işlemler sebebi ile artmış mortaliteye yol açar. Bu çalışmada NYBÜ'de bir yıl içinde invaziv alet kullanımı gelişen enfeksiyonları, izolatlarını değerlendirmeyi planladık.

Gereç ve Yöntem: Çalışmaya 2017 yılı içerisinde takip edilen 232 hasta alınmış, enfeksiyon kontrol komitesi (EKK) hemşireleri ve Enfeksiyon Hastalıkları Anabilim Dalı'nca NYBÜ'ne gerçekleştirilen vizitlerde HE tanısı almış hastalar, izolatlar, direnç profilleri, tutulum tanımları incelenmiştir.

Bulgular: Çalışmamızda NYBÜ'de yatan hastalarda mortalite $\% 27,15$, HE gelişen grupta ise mortalite $\% 56,66$ olarak bulunmuştur. En sık görülen enfeksiyon \%43,3 ile ventilatör ilişkili pnömoni (VIP) en sık etken ise \%28,9 ile Acinetobacter baumannii saptanmıştır.

Sonuç: NYBÜ'de EKK'nın sık rastlanan nozokomiyal patojenlerin yayılma ve bulaşmasına karşılık alacağı tedbirlere uyum sağlamak, standart önlemlere ve el hijyenine riayet etmek ve gereksiz invaziv alet kullanımından kaçınmak gerekmektedir. Enfeksiyon oran ve hızları değerlendirilmeli, ulusal sürveyans verileri ile karşılaştırılmaııdır. Sık karşılaşılan patojenler ve antibiyotik direnç özelliklerinin iyi tanımlanması ampirik tedavinin uygun ve vaktinde başlanmasında, morbidite ve mortalite azalmasında önemlidir.

Anahtar Sözcükler: Enfeksiyon; enfeksiyon Kontrol; yoğun bakım ünitesi.

\begin{abstract}
Introduction: The frequency of nosocomial infections (NI) are gradually increasing because of prolonged life, advancing technology, increasing invasive procedures. $\mathrm{NI}$ are mostly seen in intensive care units. $\mathrm{NI}$, developed in neurology intensive care unit (NICU), lead to increased mortality because of underlying primer diseases, general medical condition disorder, and increased invasive operations. In this study, we aimed to evaluate the use of invasive instrument,developing infections,and isolations in a year.

Methods: 232 patients (followed in 2017) are included in this study. Patients diagnosed with NI, isolates, resistance profiles, and involvement are examined in the visits to NICU by the nurses of infection control committee(ICC) and the Department of Infectious Diseases.

Results: In our study, the mortality in NICU patients is $\% 27,15$ and in $\mathrm{NI}$ group the mortality is $\% 56,66$. The most common infection is ventilator-associated pneumonia with \%43,3 (VAP) and the most common factor is Acinetobacter baumannii with \%28,9.

Discussion and Conclusion: It is necessary to coordinate with precautions (taken by ICC) against to extension and contagion of common nosocomial pathogens, to consider standart precautions, hand hygiene, and to stop unnecessary use of invasive instruments. The rate and speed of infection shoud be evaluated and compared with the national surveillance data. The well-defined common pathogens and antibiotic resistance features are important in the beginning of empiric treatment on time and in the decrease of morbidity and mortality.
\end{abstract}

Keywords: infection; infection control; intensive care units.

Corresponding (IIletişim): Ahmet Rıza Şahin, Kahramanmaraş Sütçü İmam Üniversitesi Tıp Fakültesi, Enfeksiyon Hastalıkları ve Klinik Mikrobiyoloji Anabilim Dalı, Kahramanmaraş, Turkey

E-mail (E-posta): drahmetrizasahin@gmail.com

Received (Geliş Tarihi): 11.11.2018 Accepted (Kabul Tarihi): 11.02.2019 
$\mathrm{H}$ astane yatışı öncesinde inkübasyon döneminde olmayan, yatıştan 48-72 saat sonra ortaya çıkan, cerrahi alanda 3090 gün, taburculuk sonrası 10 gün, kalıcı cihaz uygulamaları halinde 1 yıla kadar ortaya çıkan enfeksiyonlara hastane enfeksiyonları (HE) denir. ${ }^{[1]}$ Yoğun bakım üniteleri (YBÜ), hastaların genel durum bozukluğu, artmış invaziv işlemler, düşük bağışıklık yanıtı, uzamış yatış ve sık antibiyotik kullanımı sebebiyle HE'nin en sık görüldüğü hastane birimleridir. ${ }^{[2,3]}$

YBÜ'de sık ve uygunsuz antibiyotik kullanımı dirençli izolatların seçilmesine ve daha sıklıkla çoğul ilaç dirençli patojenlerce enfeksiyon oluşumuna yol açar. ${ }^{[4]}$ YBÜ'de sürveyans çalışmaları ile sık rastlanan patojen izolatların bilinmesi, antibiyotik duyarlılıklarının saptanması uygun ve başarılı ampirik tedavide yol göstericidir. ${ }^{[5,6]}$ Bu çalışmada hastanemiz nöroloji yoğun bakım ünitesinde (NYBÜ) 2017 yılında yatarak tedavi edilmiş ve HE tanısı almış hastaların epidemiyolojik özelliklerinin belirlenmesi, sık görülen patojen ve direnç özelliklerinin değerlendirilmesi amaçlanmıştır.

\section{Gereç ve Yöntem}

\section{Verilerin toplanması}

Kahramanmaraş Sütçü İmam Üniversitesi Tıp Fakültesi Hastanesi 120 yoğun bakım yatağına sahiptir. NYBÜ'de, Nöroloji kliniğinden ayrı bir alanda, ikisi izole oda olmak üzere 10 yoğun bakım yatağı mevcuttur. NYBÜ'de 48 saatten az kalan hastalar ve 48 saatten önce enfeksiyon tespit edilen hastalar çalışmada tutulmuş fakat HE gelişen gruba alınmamıştır. Enfeksiyon kontrol komitesi (EKK) hemşireleri ve Enfeksiyon Hastalıkları Anabilim Dalı NYBÜ'ne günlük vizitler gerçekleştirmektedir. Vucüt sıcaklığı $38^{\circ} \mathrm{C}$ üzeri olan tüm hastalardan periferik kan kültürü, trakeal aspirat kültürü, idrar kültürü, varsa katater kültürü, çıkarılmış katater olduğunda katater ucu kültürü, yara yeri kültür örnekleri alınmıştır. Hematolojik, biyokimyasal parametreleri incelenmiştir. Radyolojik incelemeler gerekli hallerde yapılmıştır. Hastanın fizik muayene bulguları ve klinik kondisyonu göz önüne alınarak sonuçlar birlikte değerlendirilmiştir. Hastane enfeksiyonları (HE) tanısı "Hastalık Kontrol ve Önleme Merkezi" (Centers for Disease Control and Prevention) kriterleri kullanılarak konulmuştur. ${ }^{[7]}$ Günlük vizitler sonucu oluşan notlar geçmişe yönelik olarak incelenmiştir.

\section{Kullanılan standart tanımlar}

Enfeksiyon hızı=NYBÜ'de saptanan enfeksiyon sayısı/NYBÜ'de yatan hasta sayısı x100 formülü kullanılarak hesaplanmıştır. Ayrıca NYBÜ'de saptanan enfeksiyon sayısı/tüm hastanede saptanan enfeksiyon sayısı x100 formülü ile NBYÜ'deki enfeksiyon oranı elde edilmiştir. Ventilatör ilişkili pnömoni (VIP) hızı=VIP sayısı/ventilatör günü x100 formülü ile; kateter ilişkili üriner sistem enfeksiyon (KI-ÜSE) hızı=KI-ÜSE sayısı/üriner kateter (ÜK) günü x100 formülü ile; santral venöz kateter ilişkili kan dolaşım enfeksiyonu (SVKI -KDE) hızı=SVKI-KDE sayısı/SVK günü x100 formülü ile hesaplanmıştır.

Tablo 1. NYBÜ'de yatan hastaların cinsiyet, tanı ve sonlanıma göre dağılımı

n

Cinsiyet

Kadın

Erkek

Tanısı

İskemik inme 134

Status epileptikus

GDB

İntrakranial hemoraji

Meningoensefalit

GBS

Motor nöron hastalığı

PRES

Intrakranial kitle

Parkinson hastalığı

Hepatik ensefalopati

Nörosarkoidoz

CJD

Myastenia graves

Sonlanım

Eksitus

Servise çıkış

NYBÜ: Nöroloji yoğun bakım üniteleri; GDB: Genel durum bozukluğu; GBS: Guillain Barre sendromu; PRES: Posterior reversible ensefalopati sendromu; CJD: Creutzfeldt Jacob hastalığı.

\section{Mikrobiyolojik tanımlama}

Alınan numune örnekleri kan kültür şişelerine, eozin metilen mavisi agar ve kanlı agara ekilmiştir. Kan kültür şişeleri üreme açısından aksi durum belirtilmedikçe sinyal açısından 7 güne kadar beklenerek sinyal açısından değerlendirilmiştir. Balgam, yara yeri ve kateter numuneleri Gram- boyama ve lökosit varlığı açısından incelenmiştir. İzole edilen mikroorganizmalar tanımlamak ve duyarlılık için Vitek 2 compact (BioMerieux, Marsilya, Fransa) otomatize sistemiyle tür düzeyinde tanımlanmıştır. Antibiyotik duyarlılıklarıysa Clinical and Laboratory Standards Institute (CLSI) ölçütlerine uygun olarak belirlenmiştir.

\section{İstatistik}

Tüm veriler Statistical Package for the Social Sciences (SPSS) 16.0 programına girilmiştir. Bu program aracılığı ile frekans, yüzdelik hesaplamalar ve ikili değişkenler chi-square formülü kullanılarak hesaplanmıştır.

\section{Bulgular}

2017 yılı içerisinde NYBÜ'de 232 hasta takip edildi. Ortalama yaş 65,5 olup (17-96) 132 erkek ve 100 kadın hasta mevcuttur. Hastaların tanıları ve sonlanımları Tablo 1'de sunulmuştur. Takip edilen süre boyunca toplam 30 hastada HE saptandı. Bu 


\section{Tablo 2. HE gelişen hastalar}

\begin{tabular}{|c|c|c|c|c|c|}
\hline & $\mathbf{n}$ & $\%$ & & & \\
\hline \multicolumn{6}{|l|}{ Cinsiyet } \\
\hline Kadın & 56,6 & 17 & & & \\
\hline Erkek & 43,4 & 13 & & & \\
\hline Exitus & 56,6 & 17 & & & \\
\hline Taburcu & 43,4 & 13 & & & \\
\hline Teşhis & & & \multicolumn{3}{|c|}{$\begin{array}{l}\text { Eşlik eden hastalık } \\
\qquad(\mathrm{n}, \%)\end{array}$} \\
\hline İskemik inme & 33,3 & 10 & HT & 17 & 56,6 \\
\hline Epilepsi & 33,3 & 10 & DM & 11 & 36,6 \\
\hline Hemorajik inme & 13,3 & 4 & KKY & 7 & 23.3 \\
\hline Subaraknoid kanama & 10 & 3 & KBY & 5 & 16,6 \\
\hline Viral ensefalit & 3,3 & 1 & $\mathrm{KAH}$ & 3 & 3,3 \\
\hline Motor nöron hastalığı & 3,3 & 1 & & & \\
\hline İntraserebral kanama & 3,3 & 1 & & & \\
\hline
\end{tabular}

HE: Hastane enfeksiyonları; HT: Hipertansiyon; DM: Diabetes mellitus; KKY: Konjestif kalp yetmezliği; KBY: Kronik böbrek yetmezliği; KAH: Koroner arter hastalığı.

hastalardan \%56.5 (17)'i kadın, \%43,4 (13)'ü erkektir. Ortalama yaş 72.6 (24-89) olarak bulundu. HE tanısı olan hastalardan \%56.5 (17)'i exitus olmuştur. HE gelişmeyen 202 hastanın mortalitesi \%22,7 (46) olarak saptanmıştır. HE tanısı alarak takip edilen hastalarda birden fazla eş zamanlı tanılar bulunmakta olup tanılarının dağılımı; \%33,3 (10) iskemik inme, \%33,3 (10) epilepsi, \%13,3 (4), hemorajik inme, \%13,3 (4) viral ensefalit, \%3,3 (1) subaraknoid kanama (SAK), \%3,3 (1) motor nöron hastalığı, \%3,3 (1) intraserebral kanama şeklindedir. Hastaların eşlik eden sistemik hastalıklarının dağılımı; \%56,6 (17) hipertansiyon, \%36,6 (11) DM, \%23,3 (7) KKY (\%23,3), 5 KBY (\%16,6), $3 \mathrm{KAH}(\% 3,3)$ şeklindedir. Hastaların demografik verileri ve yatış tanıları ile eşlik eden hastalıkları Tablo 2 'de belirtildi.

NYBÜ'de takip edilen 232 hastanın 286 toplam yatışı, hasta yatış günü ise 3186 saptandı. NYBÜ'de hastalarda mekanik ventilatör kullanım oranı \%0,3, kullanım günü 968 , viP hızı $\% 12,4$ 'tür. Üriner kateter kullanım oranı 0,99, kullanım günü 3160, Ki-ÜSE hızı \%2.53'tür. Santral venöz kateter kullanım oranı 0,24, kullanım günü 778, SVK ilişkili KDi hızı \%5,14'tür. Kullanılan invaziv alet günleri ve alet kullanım oranları ile enfeksiyon hızları Tablo 3 'te belirtildi.

Nöroloji yoğun bakımda hastane enfeksiyonuna neden olan 9 farklı türde mikroorganizma saptanmıştır. Bunlar içerisinde en sık Acinetobacter baumannii (\%28.9) izole edildi. Enfeksiyon etkeni mikroorganizmalar ve enfeksiyon odaklarına göre göre mikroorganizmaların dağılımı Tablo 4 'te gösterildi.

\section{Tartışma}

Son yüzyılda antibiyotiklerin keşfi ile kitlesel kullanıma girmesi bununla beraber yakın geçmişte YBÜ'de gelişen tıbbi teknoloji, profesyonel ekipmanlar sayesinde kaybedilecek bir çok hastanın yaşamasına imkan sağlanmıştır. ${ }^{[8,9]}$ YBÜ'de takip edilen hastaların komorbid hastalıkları, metabolik sorunla-
Tablo 3. İnvaziv alet kullanım gün, hız ve oranları

\begin{tabular}{lcccc} 
& $\begin{array}{c}\text { Kullanım } \\
\text { günü }\end{array}$ & $\begin{array}{c}\text { Kullanım } \\
\text { oranı }\end{array}$ & & $\begin{array}{c}\text { Enf hızı } \\
\%\end{array}$ \\
\hline Mekanik vent & 968 & 0,3 & Vip & 12,4 \\
Üriner kateter & 3160 & 0,99 & Ki-ÜSE & 2.53 \\
SVK & 778 & 0,24 & SVK ilişkili KDE & 5,14 \\
\hline
\end{tabular}

KI-ÜSE: Kateter ilişki üriner sistem enfeksiyonu; SVK: Santral venöz kateter; KDE: Kan dolaşım enfeksiyonu.

Tablo 4. Enfksiyon etkenleri ve dağılımı

\begin{tabular}{lccllc} 
HE etkenleri & $\mathbf{n}$ & $\%$ & HE lokalizasyonu & $\%$ \\
\hline Acinetobacter & 11 & 28,9 & VIP & Acinetobacter & 45,15 \\
E. coli & 6 & 15,7 & & E. coli & 23,07 \\
Klebsiella & 5 & 13,1 & & Pseudomonas & 15,3 \\
Enterococcus & 4 & 10,5 & KI-ÜSi & E. coli & 37.5 \\
KNS & 4 & 10,5 & & Klebsiella & 37.5 \\
S. aureus & 3 & 7,8 & SVK-KDE & KNS & 57,1 \\
Pseudomonas & 2 & 5,2 & & Candida & 28,5 \\
Candida & 2 & 5,2 & & Enterecoccus & 14,2 \\
Diğer & 1 & 2,6 & & Acinetobacter & 14,2 \\
\hline
\end{tabular}

HE: Hastane enfeksiyonları; ViP: Ventilatör ilişkili pnömoni; KNS: Koagülaz negatif stafikoklar; KI-ÜSE: Kateter ilişkili üriner sistem enfeksiyonu; SVK-KDE: Santral venöz kateter ilişkili kan dolaşım enfeksiyonu.

rl, düşük immün kondisyon, bilinç değişikliği gibi kompleks sorunlarıyla beraber artmış invaziv işlemler, üriner kateterizasyon, uzun süreli periferik ve satral venöz kateterizasyon, endotrakeal tüp kullanımı HE gelişim riskini arttırmaktadır. $[8,10,11]$ YBÜ'de takip edilen hastalar için HE morbidite ve mortalitenin en önemli belirleyicisidir; HE etkenlerini ve antibiyotik duyarılııklarını belirlemek mortalitenin azaltılması açısından önemlidir. ${ }^{[1,3]}$ Çalışmamızda NYBÜ'de yatan hastalarda mortalite $\% 27,15$ (63), HE gelişen grupta ise mortalite $\% 56,66$ (17), HE gelişmeyen grupta \%22,7 (46) olarak saptanmıştır. NYBÜ'de HE gelişmiş olması mortalite artışı açısından istatiksel olarak anlamlı bulundu $(p<0.05)$. Ülkemizde ve yurtdışında yapılan çalışmalarda yatarak tedavi alan $\mathrm{HE}$ geliş̧en hastalarda YBÜ ve hastane genelinde mortalite artmıştır. ${ }^{[12-14]}$

Yapılan çalışmalarda enfeksiyon oran ve hızları açısından hastaneler ve yoğun bakımlar arasında ciddi farklar bulunmaktadır. YBÜ fiziki koşulları, hasta başına düşen sağlık çalışanı, sağlık çalışanlarının enfeksiyon kontrol önlemleri hakkında aldığı eğitimler, bilgi düzeyi ve uyumu bu farkların oluşmasında etki etmektedir. ${ }^{[15,16]}$ Meriç ve arkadaşlarının ülkemizden 3. basamak hastaneleri kapsayan çok merkezli olarak yaptığı çalışmada yoğun bakımlarda enfeksiyon dansitesi 38 olarak saptanmıştır. ${ }^{[17]}$ Leblebicioğlu ve arkadaşları üniversite hastanelerinin yoğun bakımlarında enfeksiyon dansitesini 33,9 bulmuştur. ${ }^{[18]}$ Akdeniz Üniversitesi'nde yapılan bir çalışmada en yüksek dansiteler iki ayrı anestezi ve reanimasyon yoğun bakım ünitesinde (ARYBÜ) $(44,7-44,6)$ saptanmıştır. Yine ül- 
kemizden yapılan bir çalışmada ARYBÜ'de enfeksiyon dansitesi 18,5 ile en yüksek birim olarak çıkmıştı. ${ }^{[19,20]}$ Ülkemizden yoğun bakım enfeksiyonlarının irdelendiği bir çalışmada en yüksek oran NYBÜ'de \%35,1 olarak saptanmıştır. ${ }^{[21]}$ Yurtdışında NYBÜ'de gerçekleşen enfeksiyonların irdelendiği çalışmada bu oran \%24,2 bildirilmiştir. Bir diğer çalışmada \%18,5 olarak bildirilmiştir. ${ }^{[22,23]}$ Ülkemizden NYBÜ' lerin değerlendirildiği bir çalışmada ise \%15,4 olarak saptanmıştır. ${ }^{[1]}$ Bizim çalışmamızda literatürle uyumlu olarak en yüksek enfeksiyon dansitesi 20,34 ile ARYBÜ'nde, ardından 17,79 ile beyin cerrahi yoğun bakım ünitesinde saptanmıştır. NYBÜ' de bu oran 9,73 ile diğer yayınlardan düşük olarak hesaplanmıştır.

İnvaziv aletler, vücudun bariyer bütünlüğünü bozması, biyofilm oluşum kolaylığı, virülansı düşük suşlar yanı sıra daha az sayıda bakteri ile enfeksiyon oluşturabilmesi HE gelişimi açısından önemli ve sorunludur. ${ }^{[2,25]}$ Endotrakeal tüp yerleştirilen ve mekanik ventilasyon uygulanan hastaların büyük kısmında HE görülmüştür. ${ }^{[24]}$ İnvaziv alet ilişkili enfeksiyonlar sağlık hizmeti kalitesinin önemli bir göstergesidir. ${ }^{[2]]}$ Sağlık Bakanlığı ulusal sürveyans ağı verilerine göre üniversite hastanelerinin 2017 yılı NYBÜ verileri ventilatör kulanım oranı \%0,42, ViP hızı $\% 10,9$, üriner katater kullanım oranı \%0,97, Ki-ÜSE hızı \%4,2, SVK kullanım oranı \%0,33, SVKi-KDE hızı \%5,3'dir. ${ }^{[16]}$ Sağlık bakanlığı verilerine göre üniversite NYBÜ'lerde ventilatör kullanım oranı ve VIP oranı tüm NYBÜ'lere göre daha yüksektir. ${ }^{[16]}$ Üriner katater ilişkili ÜSE ve SVK ilişkili KDE hızları da benzer şekilde daha yüksek bulunmuştur. ${ }^{[16]}$ Bizim çalışmamızda; VIP hızı \%12,4, Ki-ÜSE hızı \%2,53, SVKi-KDE hızı \%5,14 olarak belirlenmiştir. Üniversite hastanelerinin sevk zincirinin son basamağı olması, komorbid hastalıkları fazla kompleks olguların uzamış yatış süreleri bunda etkili olabilir. ${ }^{[1]}$ Bizim çalışmamızda literatür ile uyumlu olarak bulunmuştur.

Ülkemizden yapılan bir çalışmada NYBÜ'de takip edilen 291 hastada yapılan bir çalışmada en sık ÜSE \%71,88 olarak saptanmıştır. ${ }^{[1]}$ ÜSE'nin sık görülmesi üriner kateterizasyon ile ilişkili olduğu düşünülmektedir. ${ }^{[1,21]}$ Bizim çalışmamızda $\% 43,3$ ile en sık pnomoni, \%26,6 ile ÜSE, \%23,3 ile KDE izlemiştir. YBÜ'de en sık görülen enfeksiyon pnomoni olup sırasıyla USE, KDE izlemektedir. Ülkemizden yayınlanan çalışmalarda, "European Prevalence of Infection in Intensive Care Study" (EPIC) gibi kapsamlı uluslararası sürveyans çalışmalarında en sık görülen enfeksiyon VIP (EPIC: \%46,9 EPIC2: \%63,5) bunu sırasiyla USE (EPIC \%17,6 EPIC2 \%14), KDE EPIC \%12 EPIC \%15,1) izlediğini göstermiştir. ${ }^{[12,13]}$ Bizim çalışmamızda da literatür ile uyumlu olarak en sık pnomoniler görülmüş bunu ÜSE ve KDE izlemiştir. YBÜ gelişen enfeksiyonlarda gecikmiş uygun antibiyotik veya uygun olmayan antibiyotik uygulamalarının artmış mortaliteye yol açtığı bilinmektedir. ${ }^{[25]}$ Bu yüzden sık görülen enfeksiyonların izolatları ve antibiyotik duyarlılıkları bilinmelidir. ${ }^{[21]}$ Sağlıklı bireylerde enfeksiyon oluşturmayan, hastane ünitelerinde kolaylıkla bulunup seçilebilen YBÜ patojenleri arasında gram negatif bakterilerle gerçekleşen HE oranları son yıllarda artış göstermektedir. Bu oransal değişmede çoğu ilaç dirençli Acinetobacter baumannii izolatları ile oluşan enfeksiyonların sıklığı önemli bir etkendir. ${ }^{[2,26]}$ Yapılan çalışmalarda pnömoni etkeni patojenlerin sıklık sırasına göre Acinetobacter baumannii, Pseudomonas aeruginosa, Staphylococcus aureus olduğu gösterilmiştir. ${ }^{[1,28]}$ Bizim çalışmamızda VIP enfeksiyonlarının etkeni \%46,15 A. Baumannii, \%23,07 Escherichia coli, \%15,3 P. aeruginosa olarak saptandı. YBÜ'de ÜSE'ye en sık E. coli'nin, ikinci sıklıkta ise Klebsiella pneumoniae'nın neden olduğu bildirilmiştir(29). Bizim çalışmamızda E. coli ve K. Pneumoniae \%37,5 ile en sık saptanan patojenler olarak saptanmıştır. Hastanemiz NYBÜ'de bu izolatlara karşı uygun doz ve süre aralıklarında ampirik antibiyotik kullanımında tercih edilmektedir.

KDE daha çok SVK ilişkili olup hızla sepsise evrilebilir. Bazı durumlarda kateterin çekilmesi tanıda veya tedavide gereklidir. SVK ilişkili KDE yüksek mortalite ile gider. ${ }^{[1]}$ En sık etken olarak koagülaz negatif stafilokoklar (KNS) ve S. aureus bildirilmiştir. [12,13] Enfeksiyon SVK'ın kullanımının herhangi bir döneminde meydana gelebilir. SVK ilişkili KDE etkenleri en sık hub yerinden geçseler de endojen oluşan bakteremi veya kandidemi sonucu da oluşabilir. ${ }^{[30]}$ Bizim çalışmamızda \%57,1 (4) ile en sık KNS, ardından Candida spp. \%28,5 (2) tespit edilmiş̧ir. Çalışmamız bu açıdan literatür ile uyumlu çıkmışır.

Çalışmamızda NYBÜ'de, ortalama yaşın yüksek olması, hastaların ek hastalıklarının fazla olması, artmış invaziv alet kullanımı, uzamış yatış süresi ve düşmüş immün kondisyon tabloya eklenince HE sıklığı artmaktadır. Bu durum uzamış hastane yatışı, artmış morbidite ve mortaliteye yol açmaktadır. Enfeksiyon kontrol komitelerinin sık rastlanan nozokomiyal patojenlerin yayılma ve bulaşmasına karşılık alacağı tedbirlere uyum sağlamak, standart önlemlere ve el hijyenine riayet etmek ve gereksiz invaziv alet kullanımından kaçınmak gerekmektedir. Enfeksiyon oran ve hızları değerlendirilmeli, ulusal sürveyans verileri ile karşılaştııılmalıdır. Sık karşılaşılan patojenler ve antibiyotik direnç özelliklerinin iyi tanımlanması ampirik tedavinin uygun ve vaktinde başlanmasında, morbidite ve mortalite azalmasında önemlidir.

Çıkar çatışması: Yazarlar arasında çıkar çatışması yoktur.

Finansal destek: Herhangi bir kurumdan finansal destek alınmamıştır.

\section{Kaynaklar}

1. Eren F., Öngün G., Ural O., Öztürk Ş. Nöroloji yoğun bakım ünitesinde bir yıllık hastane enfeksiyonu oranları: Patojenik ve klinik değerlendirme. Türk Nöroloji Dergisi 2017; 23(4), 205-10.

2. Yüce $\mathrm{ZT}, \mathrm{Alp} \mathrm{E}$. Infection control bundles for the prevention of hospital infections. Mediterr J Infect Microb Antimicrob 2016; 5: 8

3. Ok G, Gazi H, Tok D, Erbüyün K. Celal Bayar Üniversitesi Anestezi Yoğun Bakım Ünitesi'nde hastane infeksiyonlarının sürveyansı. Yoğun Bakım Dergisi 2007;7:452-57.

4. Yalçın AN. Yoğun bakım ünitesinde antibiyotik kullanımı ve direnç sorununa genel bakış. ANKEM Dergisi 2009;23(Özel Sayı):136-42.

5. Inan A, Ozgultekin A, Senbayrak Akcay S, et al. Alterations in Bacterial Spectrum and Increasing Resistance Rat in Isolated Micro- 
organisms from Device-Associated Infections in an Intensive Care Unit of a Teaching Hospital in Istanbul (2004-2010) Jpn J Infect Dis 2012;65(2):146-51.

6. Nerjaku V, Kılıç A, Küçükkaraaslan A, Baysallar M, Doğancı L. Bir askeri hastanenin yoğun bakım ünitelerindeki hastane infeksiyonlarının değerlendirilmesi. Gülhane Tıp Dergisi 2004;46(4):305-10.

7. Mangram AJ, Horan TC, Pearson ML, Silver LC, Jarvis WR. Guideline for Prevention of Surgical Site Infection 1999. Centers for Disease and Prevention, (CDC). Hospital Infection Control Practices Advisory Commitee. Am J Infect Control 1999; 27(1): 97-132.

8. Çelikel T. Dünyada ve Türkiye'de Yoğun Bakım Uzmanlığı. Yoğun Bakım Dergisi 2001; 1.1: 5-9.

9. Karabay O. Türkiye'de antibiyotik kulanımı ve direnç nereye gidiyor? Ankem Derg 2009; 23, 116-20.

10. Spencer RC. Epidemiology of infection in ICU's. Intensive Care Med 1994;20(Suppl 4):2-6.

11. Inanc, Y., Gokce, M., Tuncel, D., Inanc, Y., Ozcekic Demirhan, S., Bavli, S. Percutaneous endoscopic gastrostomy in neurology intensive care unit. IJSM 2018; 4(1), 33-5.

12. Vincent, J. L., Bihari, D. J., Suter, P. M., et al. The prevalence of nosocomial infection in intensive care units in Europe: results of the European Prevalence of Infection in Intensive Care (EPIC) Study. Jama 1995; 274(8), 639-44.

13. Vincent, J. L., Rello, J., Marshall, J., et al. International study of the prevalence and outcomes of infection in intensive care units. Jama 2009; 302(21), 2323-29.

14. Çevik MA, Yılmaz GR, Erdinç FŞ, Üçler S, Tülek N. Nöroloji yoğun bakım ünitesinde mortalite ile ilişkili faktörler ve nozokomiyal infeksiyonla mortalitenin ilişkisi. Yoğun Bakım Dergisi 2001;1:47-55.

15. Gastmeier P, Geffers C, Brandt C, et al. Effectivenes of a nationwide nosocomial infection surveillance system for reducing nosocomial infections. J Hosp Infect 2006;64(1):16-22.

16. https://hsgm.saglik.gov.tr/tr/duyurular/997-ulusal-saglikhizmeti-ilişkili-enfeksiyonlar-surveyans-agi-etken-dagilimi -ve-antibiyotik-direnc-raporu-2017.html (Alıntılama tarihi: 08.11.2018)

17. Meric M, Baykara N, Aksoy S,et al. Epidemiology and risk factors of intensive care unit acquired infections: a prospective multicentre cohort study in a middle-income country. Singapore Med J 2012;53(4):260-63.

18. Leblebicioglu H, Rosenthal VD, Arikan OA, et al. Device associated hospital-acquired infection rates in Turkish intensive care units. Findings of the International Nosocomial Infection Control Consortium (INICC). J Hosp Infect 2007;65(3):251-7.
19. İnan D, Saba R, Keskin S ve ark. Akdeniz Üniversitesi Hastanesi yoğun bakım ünitelerinde hastane enfeksiyonları. Yoğun Bakım Dergisi 2002;2(2):129-35.

20. Karahocagil MK, Yaman G, Göktaş U, Sünnetçioğlu M, Çıkman A, Bilici A, Yapıcı K, Baran Al, Binici İ, Akdeniz H. Hastane enfeksiyon etkenlerinin ve direnç profillerinin belirlenmesi. Van Tıp Derg 2011;18:27-32.

21. Öncül, A., Koçulu, S., Elevli K. Bir devlet hastanesinin yoğun bakım ünitelerinde kazanılan hastane enfeksiyonlarının epidemiyolojisi. Şişli Etfal Tıp Bülteni 2012; 46(2), 60-66.

22. Zolldann D, Poetter $C$, Hilker R,et al. Periodic surveillance of nosocomial infections in two neurology intensive care units. A valuable tool for quality management in intensive care. Anaesthesist 2003;52:690-96.

23. Dettenkofer M, Ebner W, Els T, et al. Surveillance of nosocomial infections in a neurology intensive care unit. J Neurol 2001; 248:959-64.

24. Chambless, J. D., Hunt, S. M., \& Stewart, P. S. A three-dimensional computer model of four hypothetical mechanisms protecting biofilms from antimicrobials. Applied and environmental microbiology 2006; 72(3), 2005-13.

25. Luna CM, Aruj P, Niederman MS, et al. Appropriateness and delay to initiate therapy in ventilator associated pneumoia. Eur Respir J 2006;27:158-64.

26. Karlowsky JA, Draghi DC, Jones ME, Thornsberry C, Friedland IR,Sahm DF. Surveil-lance for antimicrobial susceptibility among clinical isolates of Pseudomonas aeruginosa and Acineto $\neg$ bacter baumannii from hospitalized patients in the United States, 1998 to 2001. Antimicrob Agents Che $\neg$ mother 2003;47:1681-88.

27. Yüce A, Yapar N, Eren Kutsoylu O. İzmir Dokuz Eylül Üniversite Hastanesi yoğun bakım hastalarından izo $\neg$ le edilen Pseudomonas aeruginosa ve Acinetobacter spp. suşlarının 2000-2002 ve 2003-2006 yıllarında saptanan antibiyotik duyarlılık paternlerinin değerlen $\neg$ dirilmesi. Mikrobiyol Bul 2009;43:195-202.

28. İnanç Y, İnanç Y. An evaluation of the infection agents and the demographic characteristics of patients followed up on a mechanical ventilator in neurology intensive care: A retrospective, single center, observational study J Surg Med. 2018;2(3):262-64. DOI: 10.28982/josam.427084

29. Warren JW. Catheter associated urinary tract infections. Int J Antimicrob Agents 2001;17:299-303.

30. Sherertz RJ, Ely EW, Westbrook DM, et al. Education of physicians in training can decrease the risk for vascular catheter infection. Ann Intern Med 2000;132:641- 48. 